\title{
A ARTICULACְÃO ENTRE ESTUDOS CULTURAIS E PSICOLOGIA SOCIAL COMO PERSPECTIVA TEÓRICA PARA ANALISAR AS RELAÇÕES RACIAIS: ENTREVISTA COM ROSA CABECINHAS
}

\author{
THE CONNECTION BETWEEN CULTURAL STUDIES AND SOCIAL PSYCHOLOGY \\ AS A THEORETICAL PERSPECTIVE FOR THE ANALYSIS RACE RELATIONS: \\ INTERVIEW WITH ROSA CABECINHAS
}

JOSE LICINIO BACKES ${ }^{*}$

ORCID: https://orcid.org/0000-0001-9013-8537

A problematização das relações raciais tem ocupado cada vez mais espaço na sociedade e na universidade. Apesar das diferentes perspectivas teóricas, pode-se afirmar que elas têm em comum a preocupação em denunciar o racismo, desconstruí-lo e construir relações sociais que possibilitem a convivência entre os diferentes, sem que as diferenças sejam traduzidas em desigualdades e inferioridade. Rosa Cabecinhas situa-se nesse campo e em suas análises tem articulado os Estudos Culturais com a Psicologia Social, mostrando de forma consistente e rigorosa como práticas racistas se mantêm e como novas práticas emergem e se relacionam com outras práticas de discriminação, como as de gênero, geração e nacionalidade. Rosa Cabecinhas é doutora em Psicologia Social da Comunicação e é Professora Associada do Instituto de Ciências Sociais da Universidade do Minho. Atualmente, é Coordenadora do Programa de Doutorado em Estudos Culturais da Universidade do Minho.

ENTREVISTADOR: Em um recente evento $(21 / 11 / 2017)$ em que tive o privilégio de escutá-la e conhecê-la pessoalmente, quando do lançamento do livro Racistas são os outros(2017), ${ }^{1}$ você, como convidada para apresentar o livro e coordenar o debate, disse, entre outras coisas interessantes, que uma das razões para o compromisso de buscar desconstruir as relações racistas se relaciona com a história

\footnotetext{
'Universidade Católica Dom Bosco, Programa de Pós-graduação em Educação, Campo Grande, MS, Brasil.

"Doutor em Educação pela Universidade do Vale do Rios dos Sinos (UNISINOS). Professor Pesquisador e Coordenador do Programa de Pós-graduação em Educação da Universidade Católica Dom Bosco (PPGE) UCDB). Coordenador do Grupo de Pesquisa Educação e Diferença Cultural. E-mail: < backes@ucdb.br >.
} 
de vida do pesquisador. Isso me provoca a fazer duas perguntas, uma de ordem subjetiva e outra de cunho epistemológico. Poderia contar como sua trajetória de vida contribuiu para que você se tornasse uma pesquisadora renomada nas questões raciais de Portugal?

ROSA CABECINHAS: Ao longo do meu percurso de investigação tenho-me dedicado, sobretudo, às questões relativas ao racismo e sexismo, o que de fato está muito ligado às minhas experiências de vida. No meu caso, o meu contato com as questões raciais ocorreu na minha infância quando fui a salto ${ }^{2}$ para França e mergulhei de repente numa realidade que eu desconhecia completamente. Eu nasci numa pequena aldeia extremamente homogênea e fechada todas as pessoas falavam a mesma língua, eram da mesma cor, da mesma religião e tinham o mesmo estilo de vida. Quase todos eram camponeses de subsistência, trabalhando no campo de sol a sol, quase todos com pouca ou nenhuma escolaridade. Os meus pais têm ambos três anos de escolaridade. Naquele contexto a minha mãe era uma pessoa privilegiada por ter andado três anos na escola, quando a sua irmã mais velha, como muitas mulheres da sua geração, não teve oportunidade de ir à escola e aprender a escrever o seu nome. Portanto, a minha infância foi vivida num contexto extremamente fechado, num Portugal salazarista, quase sem contato com o mundo exterior porque não havia eletricidade na aldeia, não havia jornais (a não ser os que eram distribuídos gratuitamente aos domingos à saída da igreja), e eram poucas as pessoas que tinham rádio, o rádio a pilhas. Eu não recordo de ter, nesses primeiros anos de infância, contatado com pessoas que fossem de "raças" diferentes, a não ser nas feiras, que se realizavam uma vez por mês, e havia umas pessoas vestidas de uma forma um pouco diferente a quem chamavam ciganos, e que eram constantemente vistas como exteriores, intrusos. Quando era para comer sopa, quando as crianças se portavam mal, sempre havia a ameaça do "velhinho cigano" que vem buscar as crianças malcomportadas. Esta lenda, digamos, do "velhinho cigano" foi transformada posteriormente em outras versões. Passados alguns anos, havia a versão de que os cabo-verdianos comiam criancinhas, isto dizia-se. Eu me lembro de ouvir isso quando era criança. Depois da Revolução do 25 de abril comecei a ouvir a versão de que os comunistas comiam as criancinhas, e pronto! A pessoa começa a perceber que há um caráter de mito dessas coisas, porque, afinal, diferentes grupos assumiam este papel de sinalizadores de certo pânico moral. Mas, voltando à questão da infância, quando tinha cinco anos e meio fui a salto para França. Os meus pais pagaram 
a um passador para me levar nessa travessia clandestina. Quando cheguei à França, me deparei com um ambiente completamente diferente daquele em que eu vivia na minha pequena aldeia, onde toda a gente era basicamente igual, e recordo-me, uma coisa que me ficou na memória, foi que, na primeira escola que eu frequentei, fui colocada no fundo da sala, juntamente com o colega, na mesma carteira; um colega que, tal como eu, vivia num bairro de pequenas caravanas, nos arredores de Paris. Tanto quanto eu me recordo, nós tínhamos quase sempre as mesmas classificações, "insuficiente" ou "muito insuficiente". Não me recordo de absolutamente nada do que a minha professora dizia, mas recordo-me de ela dizer uma coisa que me marcou: les gens de voyage sont comme ça ["as pessoas da viagem são assim”]. Estava a nos dizer que nós, como éramos pessoas da viagem (uma vida itinerante, na altura eu ainda era uma imigrante indocumentada), ou seja, sendo ciganos, tínhamos necessariamente más notas, más classificações. Estávamos condenados a um destino comum. E aquilo foi algo que me perturbou, porque lembrava-me de que, na minha aldeia, os ciganos eram uma coisa diferente do que eu era - eu era uma coisa, e eles eram outra. E eu, ali naquele contexto, eu era cigana. Então, tanto quanto me recordo, aquele foi o primeiro momento em que eu pensei "o que é isso, o que que nós somos"? Aquilo, na altura, chocou-me, mas pouco a pouco, como se costuma dizer, "primeiro estranha-se, depois entranha-se". Pouco a pouco, aquela ordem de que aqui estão os ricos, aqui estão os pobres, aqui estão... Muitas vezes, os lugares dos pobres são os lugares dos que têm a pele mais escura, dos que falam uma língua diferente, dos que têm uma cultura percebida como marginal. Essas coisas todas começaram a aparecer muito misturadas e muito conflituosas, e, portanto, foi essa realidade que eu vivi nesses anos em que estive a viver na pequena caravana nos arredores de Paris. Era uma realidade extremamente diversa, para a qual eu não estava preparada para enfrentar, saindo da minha pequena aldeia portuguesa. Quando regressei para Portugal, um ano antes do 25 de abril, a minha pequena aldeia continuava na mesma, e o regresso foi muito difícil, pois eu mais uma vez fui vista como estrangeira, e como uma ameaça, pois subia às árvores, o que não era um comportamento admissível para uma rapariga. Também não era admissível escrever com a mão canhota, ao contrário do que acontecia nas escolas que frequentei em França. Enfim, rapidamente me tornei a "ovelha negra", como se costumava dizer. As pressões para a homogeneização cultural eram brutais. Pouco a pouco, fui assimilando os pânicos morais dominantes e os grupos dos quais eu 
devia me distanciar foram sendo diferentes. Ouvi essas tais histórias circulantes sobre os cabo-verdianos que comem criancinhas, o que é absolutamente aterrador. Isso aprendia-se muito também com o fato de, entretanto, esses grupos serem um grupo extremamente marginalizado na sociedade portuguesa. Depois passei a perceber de onde é que vinham esses medos infundados, mas que eu própria, de certa maneira, apesar de também já ter sido vítima de alguns desses medos, apesar de tudo, não deixei de os sentir num primeiro momento. Isto ilustra o poder das narrativas dominantes sobre determinados grupos, o que acaba por influenciar muito a forma como nos relacionamos com os "outros".

ENTREVISTADOR:Em relação à pergunta de cunho epistemológico, você tem transitado principalmente em dois campos que se assumem como interdisciplinares e, como tais, possibilitam articulações com outras áreas disciplinares. São eles os Estudos Culturais e a Psicologia Social, que criticam a suposta neutralidade do conhecimento científico. Inclusive, já na sua tese, você denunciava o caráter eurocêntrico e androcêntrico da ciência. Como a articulação desses dois campos, junto com conhecimentos de outras disciplinas, amplia as possibilidades de pesquisar as relações raciais fora da lógica eurocêntrica e androcêntrica?

ROSA CABECINHAS: Bem, é uma questão tão complexa que, de fato, se poderia ocupar a tarde toda para responder... Se calhar, começaria também com o meu próprio percurso de investigação, porque eu fui me deslocando de um campo para o outro... ou melhor, fui tentando integrar diferentes campos, na tentativa de ultrapassar alguns limites da investigação, de fato, eurocêntrica e androcêntrica. Digo "tentativa" porque todo o processo de construção da ciência, o nosso vocabulário, os nossos métodos, etc., estão marcados por uma lógica que bebe nessa história da ciência e que, obviamente, subjaz à nossa maneira de pensar e agir enquanto cientistas num determinado contexto. Como referi, eu quando comecei a minha investigação, interessava-me pelos processos de discriminação social, principalmente pelas questões de racismo e sexismo. No meu Mestrado, tentei estudar esses dois "ismos" conjuntamente, mas optei por estudar isso focando nos processos cognitivos individuais. Por que fiz essa opção? Essa opção - e isso liga-se à pergunta que você me fez -, essa opção deveu-se ao estado da arte na altura, pois comecei o mestrado no início dos anos de 1990, na Psicologia Social. A Psicologia Social mainstream, ${ }^{3}$ na altura, era ahistórica, não tinha... Claro que já havia a teoria das 
representações sociais, que foi uma teoria que integrou elementos da Antropologia, da Sociologia, etc., mas essa ligação com a história, com a cultura, é mais evidente hoje. A Psicologia Social mainstream nos anos noventa, e ainda hoje, é muito uma Psicologia Social de laboratório, com o controle e manipulação de variáveis. $\mathrm{Na}$ altura, o que estava, digamos, na moda era estudar o que se designa por "grupos mínimos", na linha da investigação feita por Tajfel (1981). É que ele mostrou que a condição mínima necessária para haver um favoritismo pelo próprio grupo tinha a ver com a existência de um rótulo desse grupo, ou seja, não é preciso que haja uma história de conflito ou incompatibilidade de interesses para desencadear a discriminação, basta que o grupo tenha uma existência psicológica, isto é, que a pessoa se reconheça como pertencendo a um grupo e atribua significado a essa pertença, significado esse que é determinado pela comparação com outros grupos em dimensões consideradas relevantes num determinado contexto. Eu, na altura, decidi estudar os efeitos da categorização social, nomeadamente o efeito da homogeneidade do exogrupo, que na altura se considerava um efeito universal. Ou seja, todos os grupos considerariam os grupos dos outros como mais homogêneos do que o seu próprio grupo, porque a única coisa que interessaria, o único nível de análise que interessaria seria essa comparação endogrupo, ou seja, o grupo próprio, e exogrupo, o grupo do outro. Ora bem, já tinha havido alguns estudos na área de Psicologia Social, embora não fossem correntes dominantes, que chamavam a atenção para o papel da história dos grupos, o estatuto social desses grupos e também as marcas exteriores de pertença ou não a esses grupos. E foi assim que comecei a estudar a questão da discriminação, tentando conjugar esses vários níveis de análise, portanto, desde o nível individual, dos processos cognitivos, mas muitas vezes inconscientes, até o nível mais societal, mais estrutural, que tem a ver com as posições de poder, ou o estatuto social relativo na sociedade. Isso permitiu-me perceber que, de fato, esses efeitos não são simétricos. Ou seja, os tais enviesamentos cognitivos, nomeadamente o efeito de homogeneidade do exogrupo, não são simétricos, nem universais, dependem do contexto envolvente e do estatuto social relativo dos grupos. $\mathrm{E}$ foi a partir da necessidade de estudar o contexto envolvente que eu entrei, já numa fase posterior das leituras, na Antropologia, na História e, finalmente, nos Estudos Culturais. Atualmente, a Psicologia Social está muito mais aberta às questões históricas e culturais, nomeadamente a Psicologia Social Crítica está muito mais aberta a este diálogo interdisciplinar do que no início dos anos $90 \ldots$ Atualmente, há mais consciência dessa 
necessidade de articulação. Nos Estudos Culturais, a minha entrada deu-se pelo fato de... Na altura, quando terminei a tese de doutorado (2002), apesar de eu ter feito um esforço para fugir ao eurocentrismo, quase toda a bibliografia que citava, não toda, mas quase toda, acabava por ser daquilo que atualmente se chama o norte global, com poucas referências a autores africanos, asiáticos, ou da América Latina. Foi essa necessidade de ir para além da literatura norte-americana e europeia mainstream, que me levou a entrar nos Estudos Culturais. Fazer esse percurso de tentar mobilizar diferentes leituras, diferentes contextos culturais, isso levou-me a constatar a necessidade de desenvolver projetos de ensino e de investigação, em que este diálogo fosse possível. É isso que tenho tentado fazer. No que diz respeito às questões raciais, eu estudei, sobretudo, a forma como o racismo foi estudado na Europa e na América do Norte, precisamente o que se constitui como a ciência dominante. Nos últimos anos, tenho lido cada vez mais os autores latino-americanos e africanos, e isso permite dar-me conta da enorme complexidade das dinâmicas culturais humanas.... mas, por muito que eu leia autores de diferentes contextos culturais, eu não deixo de ser uma pessoa ocidental num determinado contexto específico; portanto, a minha forma de olhar para a realidade será sempre marcada por isso, mas também pelas migrações que fui fazendo ao longo da minha trajetória de vida.

ENTREVISTADOR: Você tem feito uma discussão sobre estereótipos sociais, processos cognitivos e normas sociais e destaca a emergência de "novos" racismos e "novos" estereótipos. Quais são os racismos e estereótipos que, na contemporaneidade, estão mais evidentes? A que se deve a manutenção de velhos estereótipos ao mesmo tempo em que surgem novos? Como os Estudos Culturais, na articulação com a Psicologia Social, podem contribuir no processo de desconstrução dos estereótipos?

ROSA CABECINHAS: Atualmente nós estamos a viver uma fase em que aquilo que nós achávamos que estava ultrapassado voltou para as luzes da ribalta. Por exemplo, quando eu defendi a minha tese de Doutoramento, começavam a emergir estudos sobre os novos racismos, os novos sexismos, e havia quase que a ilusão de que os velhos sexismos e os velhos racismos faziam parte do passado. Hoje em dia, nós somos confrontados com o fim dessa ilusão de uma forma muito clara. Claro que, quando nós - e isso eu discuti na tese -, quando nós falamos nos "novos", é importante ver até que ponto eles bebem nos "velhos"; inclusive, essas tais narrativas dominantes são 
constantemente reatualizadas no espaço público. Portanto, os novos são na realidade velhos, mas são expressos com uma nova linguagem, uma nova aparência. Na altura, eu discuti, por exemplo, a relação entre xenofobia e xenofilia, em que às vezes aquilo que parece nãodiscriminatório, porque se elogia o outro - "é tão bonito", "dança tão bem", "canta tão bem", "tem umas roupas tão giras", etc. Eu falei, então, do papel lúdico, para o qual muitas vezes são remetidas determinadas minorias étnicas e raciais. Isso colide com a permanência da discriminação em que se atribui, em que se continua a atribuir, o papel ativo ao grupo dominante, ou seja, embora a linguagem tenha mudado, as dicotomias básicas entre aqueles que supostamente são mais capazes e aqueles que não o são, as dicotomias básicas, de certa forma, têm permanecido ao longo do tempo. Embora tenham sido feitos muitos progressos nas últimas décadas em Portugal - sobretudo, desde a Revolução de Abril e o fim da ditadura -, há muita coisa que continua a permanecer implicitamente, e essas hierarquias raciais... as hierarquias do chamado racismo científico, que já foi descredibilizado cientificamente, continuam presentes, embora de forma dissimulada, na esfera pública. Neste momento, pouca gente ousaria dizer que há raças superiores e raças inferiores. Apesar de tudo, as hierarquias raciais clássicas mantêm-se na mente das pessoas e, de certa forma, acabam por ser reproduzidas pelas instituições. Embora haja leis que tentam promover a mudança social e promover igualdades de oportunidades. Apesar dessas leis, a "raça", a cor da pele, especificamente, continuam a marcar a trajetória de vida das pessoas, a determinar diferentes oportunidades. Portanto, continua a haver racismos. Por exemplo, a Psicologia Social durante muito tempo focou-se nas percepções dos grupos dominantes face ao "alvo" da discriminação, o foco acabava por ser sempre o que o grupo dominante pensa do grupo dominado, o que o "agente" pensa da "vítima". Os Estudos Culturais, precisamente por terem surgido e terem como matriz essa atenção ao que é cotidiano, ao que está nas margens ou ao que é subalternizado, ao que é invisibilizado na esfera pública, etc., permite outro olhar, esse confronto com as narrativas de resistências, as narrativas de empoderamento, etc. etc. Portanto, dá para olhar a partir de diferentes prismas. Há pouco tempo, foram publicados os resultados do European Social Survey, que é um inquérito social que começou a ser feito no início do milênio; têm sido feitas várias rondas, o que nos permite comparar diversos países europeus. Recentemente, foram incluídas algumas questões sobre o racismo biológico, algo que se pensava já estar, digamos, apagado da esfera pública, mas, de fato, esse racismo 
não morreu, ele continua evidente nas respostas recentes feitas com amostras representativas da população europeia nos diversos países. Portanto, continua a ser uma realidade. O sexismo flagrante também. Nós temos uma legislação que atualmente tenta combater os efeitos perversos de uma mentalidade que sempre remeteu a mulher para a esfera privada e sempre reduziu o seu papel social, mas, apesar de tudo, basta-nos abrir as páginas de alguns jornais ou ver televisão, blogs e redes sociais, para vermos o quão esses velhos sexismos são evidentes. Não são evidentes apenas nas declarações do Trump ou nas declarações "populistas" de líderes de extrema direita na Europa. Às vezes parece que se quer reduzir o problema do racismo e do sexismo a casos isolados, a pessoas isoladas, que são vistas como ignorantes ou prepotentes, ou outra coisa qualquer, mas apesar de tudo como um problema isolado, portanto, minoritário, só está na cabeça de algumas pessoas. Não, é muito mais abrangente do que isso. Ainda em relação aos novos racismos e aos velhos racismos, queria mencionar que uma das dimensões que permanecem, não só esta questão da hierarquização implícita de determinados grupos humanos, mas também continua a circular na esfera pública um modelo de pessoa humana que é personificada no homem branco, de classe média, heterossexual, etc., ou seja, como se isso fosse a norma e o resto fosse desvio. Isso continua, de certa forma, a existir. Portanto, determinados grupos, nós tratamos de uma forma mais estereotipada como se fossem uma massa homogênea, enquanto outros, estamos muito mais atentos à sua distintividade individual, à sua pessoa. Os outros são, digamos, despersonalizados, tornados invisíveis enquanto pessoas.

ENTREVISTADOR: Você sistematicamente aponta em suas publicações a necessidade de pesquisar os diferentes processos de discriminação de forma articulada, com destaque para questões de raça/etnia, gênero, classe, crença e geração. O desafio parece ser como mostrar essa articulação sem deixar de apontar as especificidades de cada processo. No Brasil, especificamente, os estudos no campo das relações raciais têm tido o desafio permanente de não ficarem subsumidos nos estudos de classe. Isso também tem ocorrido em Portugal? Como você tem lidado com esse desafio? Parece-me que tanto os Estudos Culturais quanto a Psicologia Social nos ajudam a evitar os reducionismos, seja de classe, raça/etnia, gênero.

ROSA CABECINHAS: É uma questão muito interessante. Não se pode pensar a questão do racismo como uma questão de preto e branco, ou seja, dicotomizando e tendo em conta apenas esses dois 
grupos, esquecendo outros grupos ou dando menos atenção a outros grupos que têm sido também vítimas de racismo, por exemplo, os "indígenas" na Austrália, os "povos originários" na América Latina; em Portugal, em relação aos ciganos, etc. etc. Portanto, muitas vezes, pensa-se no racismo como tendo apenas um agente e apenas um alvo. É necessário complexificar essa questão. As ligações com a classe social são também muito pertinentes porque, por exemplo, nos primeiros estudos que eu fiz, quando eu perguntava às pessoas "o que era uma raça", "o que era um grupo étnico", elas quase definiam as coisas da mesma forma, fazendo uma associação entre características biológicas e características culturais. Por exemplo, quando pedia para as pessoas descreverem "os angolanos" ou "os portugueses", aparecia muito mais a cor da pele para definir um angolano do que aparecia a cor da pele para definir um português. Da mesma forma que aparecia muito mais o fato de ser pobre para definir o que é um angolano, um cabo-verdiano, do que para definir um português. Ou seja, as condições sociais e a cor da pele apareciam muito mais como definidoras dos grupos minoritários, neste contexto, do que do grupo majoritário. Eu, pessoalmente, não me debrucei sobre os estudos de classe. $\mathrm{O}$ meu foco tem sido, sobretudo, o racismo e o sexismo, mas não podemos ignorar as interseccionalidades, olhar para as várias matrizes da opressão e do privilégio. Eu acho que tem sentido continuar a estudar em profundidade cada uma dessas dimensões porque elas são suficientemente complexas para fazer estudos interessantes e para problematizar o mundo em que vivemos. Fazer estudos que cruzem essas diferentes dimensões, obviamente, é um desafio, e, na literatura sobre as interseccionalidades têm se cruzado, sobretudo, raça, gênero e classe social, mas há outras que também são muito relevantes, e é quase que impossível a gente ir desdobrando, desdobrando, desdobrando em todas as dimensões que seriam relevantes analisar; por isso, a nossa pesquisa, no momento concreto, é sempre feita de escolhas. No meu caso, em concreto, ainda há muita coisa que está por fazer, há mais coisas que estão por publicar. Por exemplo, este estudo que referi, que envolve vários países de língua oficial portuguesa, ainda muito pouco está publicado, mas no meu trabalho atual tento fazer precisamente este cruzamento, mas também tendo em conta as questões de geração. As questões de geração são importantes porque têm a ver com a mentalidade e com a educação à que a pessoa teve acesso e também com as normas sociais em que foi educada. Isso ajuda-nos muito a explicar também a forma como a pessoa percebe a realidade, como 
lida com os diferentes grupos, mas também como se vê a si própria. Às vezes, vejo nos jornais, por exemplo, a dizer que as pessoas mais velhas e com menos habilitação escolar são as mais racistas. É uma coisa que me dói! Porque, muitas vezes, mede-se o racismo a partir de questões estereotipadas. Os jovens, nomeadamente os estudantes universitários, estão super habituados a responder e, muitas vezes, estão também conscientes das normas sociais do que é politicamente correto responder nessa circunstância, e conscientemente ou não, tendem a dar respostas de modo a promover uma imagem positiva de si próprios. As pessoas mais idosas - por exemplo, num Portugal rural e onde o analfabetismo ainda é elevado - que não tiveram acesso à educação, projetam nas suas respostas aquela mentalidade salazarista, em que muitos de nós fomos educados. Eu tive sorte de o 25 de Abril dar-se quando eu tinha nove anos. Demorou um tempo até chegar à minha aldeia, mas chegou. Às vezes, pela forma como se fazem essas triangulações, os roteiros, os mais velhos são necessariamente mais preconceituosos do que os mais novos. As pessoas que vivem no meio rural são necessariamente mais preconceituosas do que as pessoas que vivem no meio urbano, embora ainda continuem na esfera pública referências à ruralidade como sinônimo de ignorância. Temos que olhar para esses dados com atenção e ver o que eles realmente significam, porque, muitas vezes, são produtos da forma como se mede aquilo que a se está a tentar medir. Por exemplo, por falar em questões de medida, a Psicologia Social mainstream utilizava quase só o método experimental. Atualmente, tem muito mais variedade metodológica, e eu acho particularmente interessante comparar os resultados obtidos através de metodologias; por exemplo, as narrativas de vida, a forma como a pessoa apresenta a sua vida durante uma entrevista autobiográfica, e os dados que se obtêm em laboratório, supostamente um meio controlado em que as pessoas sabem que estão a ser observadas com um determinado objetivo. Isto permitenos também jogar com aquilo que é o significado social, do que as pessoas estão a dizer e a forma como as normas sociais são reativadas a cada contexto. Eu comecei por fazer experiências no laboratório e ultimamente praticamente só tenho feito entrevistas e grupos focais. Portanto, desloquei-me do mais quantitativo para o mais qualitativo, mas eu vejo qualidade nessas várias formas de ver e de estudar.

ENTREVISTADOR: Para finalizar, uma questão que parece que nos preocupa neste momento no mundo, com destaque para quem está investigando no campo das relações raciais. Estamos vivenciando uma onda de conservadorismo, com a intensificação de xenofobia, 
racismo, sexismo, fundamentalismo religioso, o que tem ocasionado o ódio ao diferente. No Brasil, estamos vivendo isso de forma intensa desde 2015. Nos Estados Unidos, tivemos a eleição de Donald Trump, que você já lembrou que não é um caso isolado; na Europa, os movimentos de direita estão ganhando força. Como os Estudos Culturais, em articulação com a Psicologia Social, podem contribuir para entender esses fenômenos?

ROSA CABECINHAS: As suas perguntas são sempre tão complexas e com tantas linhas por onde seguir! Aquilo que se passa no Brasil atualmente, eu assisto com muita perplexidade e tristeza. As notícias com que somos confrontados mostram-nos o ódio ao que é pobre, ao que é diferente, mas o diferente de determinada forma. Porque há determinado diferente que se gosta, que se cultiva, mas o diferente não é simplesmente uma questão de diferença, é também uma questão de inferiorização e de hierarquização. No espaço público, na publicidade, por exemplo, está sempre a referir-se a diferença, toda gente quer ser diferente, toda gente quer ser original. Portanto, em termos de consumos culturais há alguma abertura ao diferente, as pessoas gostam de ouvir música diferente, gostam de ir num restaurante "étnico", gostam de ter um vestido com cores com inspiração africana, por exemplo. A diferença que se estigmatiza é uma diferença que é colocada num patamar de inferiorização e, em alguns casos, de desumanização, ou seja, é como se aquela pessoa não fosse realmente uma pessoa, fosse apenas um representante homogêneo de um grupo que supostamente não faz nada para que a sociedade progrida. Ainda recentemente, tivemos na Europa uma pessoa, um deputado, que disse que "as mulheres tinham que ganhar menos" porque eram "mais fracas e menos inteligentes". Portanto, é um tipo de discurso que já não se esperaria, de fato, ter no espaço público. Simultaneamente, a denúncia também tem tido mais visibilidade na esfera pública. Portanto, esses dois movimentos coexistem... Por exemplo, houve uma altura em que se achava que a palavra feminismo estava morta. Atualmente o feminismo reemergiu no espaço público, mas isso não significa que, apesar de ter sido uma das palavras do ano... No final do ano, costumam-se fazer muitos tops, o top das dez pessoas, o top dos dez acontecimentos, o top das dez palavras do ano. Recentemente, uma das palavras do ano foi fake news. Isto leva-nos para o Trump e a manipulação das notícias, a insegurança que isso traz na nossa vida cotidiana, mas feminismo foi também uma das palavras do ano... Paralelamente, o sexismo explícito e flagrante continua a existir, e o mesmo se passa com a questão 
racial. Fala-se de racismo, combate-se o racismo, mas ele continua a existir e continua a ter uma forma não só sutil, mas também muito flagrante, porque continua a existir, porque de fato toda a sociedade está organizada de uma forma nestas tais hierarquias que foram sendo consolidadas, mas que estavam por estar presentes não só na mente das pessoas, mas também na forma como as instituições funcionam, declaradamente ou não. E essa inferiorização do outro, que é visto como menos capaz - ele é pobre porque merece ser pobre, porque nunca fez nada para deixar de ser pobre -, não se vê que ele teve falta de oportunidades. Embora se discuta tanto a questão da produção da igualdade de oportunidades - e a igualdade é de fato um dos valores proclamados -, simultaneamente, a ilusão da meritocracia leva-nos a esquecer que há, de fato, pessoas que continuam a ter oportunidades desiguais. Enquanto isso continuar a acontecer, eles continuam a ser vistos como outros, ou seja, são vistos como não contribuindo positivamente para o desenvolvimento; noutros outros casos, são vistos como ameaça. Em Portugal e em outros países, sobretudo agora, nas situações de crise, em que as pessoas estão numa situação de maior vulnerabilidade, a percepção da ameaça, muitas vezes, tornase mais determinante. E esse é um dos fatores que contribui para a discriminação, mas está longe de ser o único.

\section{REFERÊNCIAS}

JESUS, D.; CONCEIÇÃO, F.; MARQUES, M. M. (Orgs). Racistas são os outros: contribuição ao debate lusotropicalista em África, Brasil e Portugal. Salvador: Afirme-se, 2017.

CABECINHAS, R. Racismo e Etnicidade em Portugal: uma análise psicossociológica da homogeneização das minorias. Tese (Tese em Ciências da Comunicação). UMINHO. Braga, 2002. Disponível em: https://repositorium.sdum.uminho.pt/bitstream/1822/25/1/ TESE_RC_FINAL.pdf

PORTELA, J.; NOBRE, S. Entre Pinela e Paris: emigração e regressos. Análise Social, v. 36, n. 161, p. 1105-1146, 2001.

TAJFEL, H. Human groups and social categories: Studies in social psychology. Cambridge: Cambridge University Press, 1981.

\section{NOTAS}

${ }^{1} \mathrm{O}$ livro foi organizado por Danila de Jesus Fernando Conceição e Margarida Marques. O evento foi realizado na Livraria Centésima Página, localizada em Braga, Portugal.

${ }^{2}$ A expressão "fui a salto" quer dizer que foi de forma clandestina, sem visto de entrada. Durante a ditadura salazarista em Portugal, muitos portugueses saíram dessa forma de 
Portugal, com destino, principalmente, para a França. O governo francês, com certa facilidade regularizava a situação dos que chegavam cladestinamente. (PORTELA; NOBRE, 2001).

${ }^{3}$ Quer dizer a Psicologia corrente, a praticada no momento.

Submetido: 09/03/2018

Aprovado: 21/11/2018

Contato:

José Licínio Backes

Rua das Paineiras, n. 1000

ap. 32 - Bairro Gomes

Campo Grande $|\mathrm{MS}|$ Brasil

CEP 79.022-110 